Check for updates

Cite this: Chem. Sci., 2019, 10, 10894

๑ All publication charges for this article have been paid for by the Royal Society of Chemistry

Received 6th August 2019

Accepted 12th October 2019

DOI: $10.1039 / \mathrm{c} 9 \mathrm{sc03914g}$

rsc.li/chemical-science

\section{One-pot syntheses of irida-polycyclic aromatic hydrocarbons $\uparrow$}

\author{
Yu Xuan Hu,,$^{a}$ Jing Zhang, $\dot{t}^{a}$ Xiaoyan Wang, ${ }^{a}$ Zhengyu Lu, ${ }^{b}$ Fangfang Zhang, ${ }^{a}$ \\ Xiaofei Yang, ${ }^{a}$ Zhihua Ma, ${ }^{a}$ Jun Yin, (D)*a Haiping Xia (D) ${ }^{b}$ and Sheng Hua Liu (D) *a
}

Metalla-analogues of polycyclic aromatic hydrocarbons (PAHs) have captivated chemists with their fascinating structures and unique electronic properties. To date, metallabenzene, metallanaphthalene and metallaanthracene have been reported. Metalla-analogues with more complicated fused rings have rarely been reported. Herein, we have successfully synthesized a series of new iridafluoranthenes and fused-ring iridafluoranthenes ranging from pentacyclic to heptacyclic metallaaromatic hydrocarbons in high yields under mild reaction conditions for the first time. Their photophysical and redox properties were also explored using UV-vis spectroscopy and electrochemistry combined with TD-DFT calculations. The present work may offer an important guideline for the design and construction of new polycyclic metallaaromatic hydrocarbons and metalla-nanographenes.

\section{Introduction}

Polycyclic aromatic hydrocarbons (PAHs), as important components in the field of organic chemistry, have attracted a significant amount of attention due to their wide range of applications in organic light-emitting diodes, ${ }^{1}$ field-effect transistors ${ }^{2}$ and organic photovoltaic cells. ${ }^{3}$ Since the first metallabenzene (Scheme 1) was reported by Roper et al. in $1982,{ }^{4}$ scientists have devoted enormous efforts to developing transition metal-containing metalla-aromatics. ${ }^{5}$ However, only very limited systems, including metallanaphthalene, ${ }^{6}$ metallaanthracene, ${ }^{7}$ metallaphenanthrenes, ${ }^{\mathbf{8}}$ metallabenzynes, ${ }^{\mathbf{9}}$ metallanaphthalynes, ${ }^{\mathbf{1 0}}$ metallaanthracynes, metallaphenanthrynes ${ }^{\mathbf{1 1}}$ and metallapentalenes, ${ }^{\mathbf{1 2}}$ have been reported over the past few decades. Moreover, metalla-analogues of PAHs containing multiple fused rings have rarely been reported until now. Among these developed systems, only a handful of examples involve irida-PAHs.

In 2017, Wright et al. successfully synthesized the first iridaanthracene complex. ${ }^{7}$ In another recent breakthrough, Bolaño et al. reported a novel iridanaphthalene compound in a high yield of $74 \%$ from its corresponding methoxy(alkenyl)

${ }^{a}$ Key Laboratory of Pesticide and Chemical Biology, Ministry of Education, College of Chemistry, Central China Normal University, Wuhan 430079, P. R. China. E-mail: yinj@mail.ccnu.edu.cn; chshliu@mail.ccnu.edu.cn

${ }^{b}$ Department of Chemistry, Shenzhen Grubbs Institute, Southern University of Science and Technology, Shenzhen 518055, P. R. China

$\dagger$ Electronic supplementary information (ESI) available: Crystallographic details and NMR and HRMS data. CCDC 1940387, 1940396, 1940398, 1940533, 1940389, 1940391, 1940392, 1940394, 1940397 and 1940400. For ESI and crystallographic data in CIF or other electronic format see DOI: 10.1039/c9sc03914g

\$ These authors contributed equally to this work. carbeneiridium compound by using an intramolecular $\mathrm{C}-\mathrm{H}$ activation reaction. ${ }^{6 \boldsymbol{b}}$ In 2018 , they further developed iridaphenanthrene, iridanaphthalene and iridaanthracene from their corresponding methoxy(alkenyl)carbeneiridium intermediates via reactions of $\left[\operatorname{IrCp} * \mathrm{Cl}(\mathrm{NCMe})\left(\mathrm{PMe}_{3}\right)\right] \mathrm{PF}_{6}$ with diarylpropargyl alcohols. ${ }^{8}$ In the present work, we have proposed a one-pot synthetic route to obtain a series of pure iridafluoranthenes in high yields $(70-87 \%)$ by using $\operatorname{IrCp} * \mathrm{Cl}_{2}\left(\mathrm{PMe}_{3}\right)$ and 9-ethynyl-9-fluorenol derivatives as reagents (Scheme 2), all of which were successfully embedded

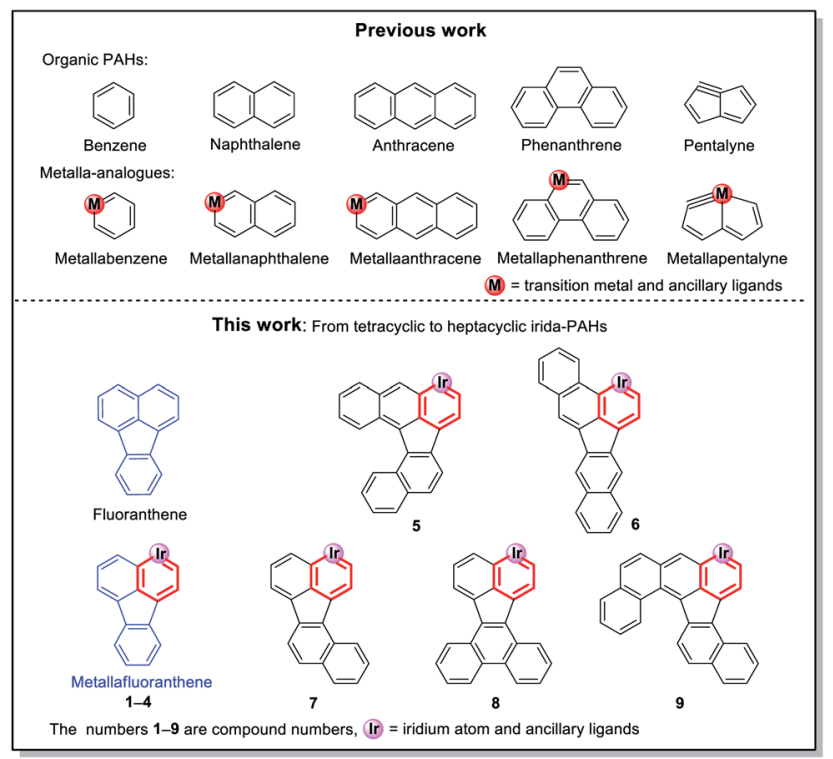

Scheme 1 Organic PAHs and metalla-analogues. 

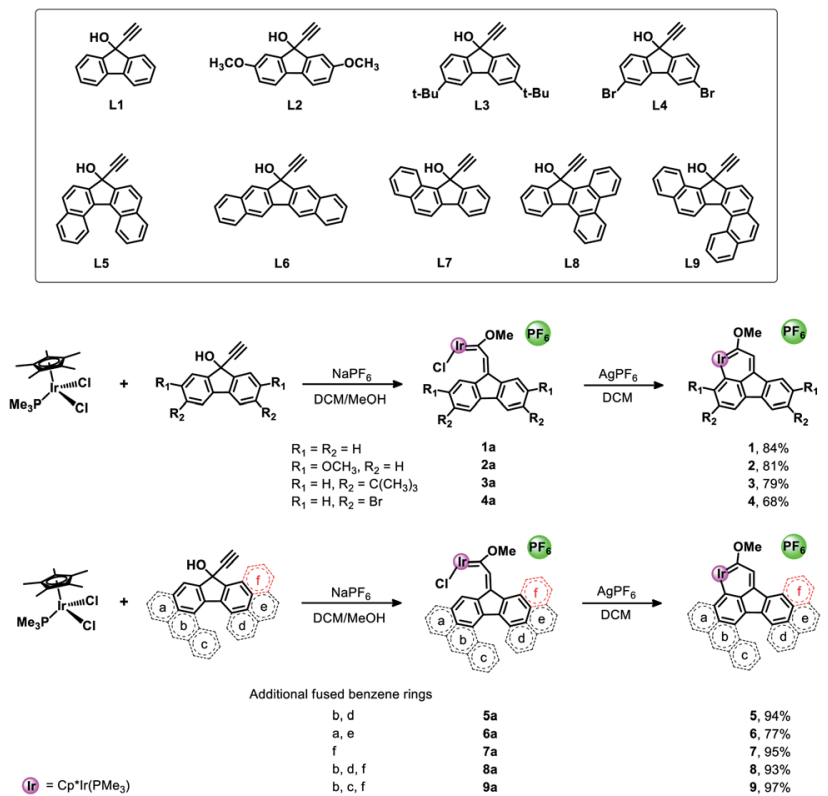

(11) $=\mathrm{Cp}^{*} \mathrm{Ir}\left(\mathrm{PMe}_{3}\right)$

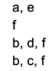

$5 a$
$6 a$
$7 a$
$8 a$
$9 a$

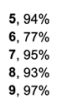

Scheme 2 Synthesis of target complexes 1-9.

into a fused five-membered ring to achieve higher conjugation. In the solid state all the new compounds are stable in air and can be stored in contact with the atmosphere for half a year without any signs of decomposition. To the best of our knowledge, the present work is the first case involving synthesis of metallafluoranthenes to date. Specifically, compounds L5-L9 were used to produce complexes 5-9 with the most abundant fused rings and high conjugation, which did not involve any isomerization and thus maintained high yield and high purity. In addition, diverse polycyclic metallaarenes, including four tetracyclic complexes (1-4) and pentacyclic (7), hexacyclic (5, 6 and 8) and heptacyclic (9) complexes, have been presented in this work. Although there are several reports on nitrogen- or oxygen-containing polycyclic metallaaromatics ${ }^{13}$ this series of new structures that contain more than four fused rings in the polycyclic skeletons consisting of a metal atom and carbon atoms only, is unprecedented.

\section{Results and discussion}

As depicted in Scheme 2, the target complexes (1-9) were synthesized by a one-pot method in high yield (70-87\%) under mild reaction conditions. Specifically, as shown in Scheme $\mathrm{S} 1, \uparrow$ a solution of $\mathrm{Cp} * \mathrm{IrCl}_{2}\left(\mathrm{PMe}_{3}\right), \mathrm{NaPF}_{6}$ and a pro-ligand (L1L9, respectively) in methanol was stirred at room temperature overnight, and then methanol was removed under vacuum and the residue was dissolved in dichloromethane. Subsequently, $\mathrm{AgPF}_{6}$ was added and the mixture was further stirred for 5 minutes to obtain the corresponding target complex (1-9). Furthermore, we propose a possible reaction mechanism according to the previous report of Bolaño et al. ${ }^{14}$ by taking complex 1 as an example. As shown in Scheme S3, $\dagger$ initially, de-coordination of one chloride from $\mathrm{Cp}^{*} \mathrm{IrCl}_{2}\left(\mathrm{PMe}_{3}\right)$ occurred, which is followed by further coordination of alkynol compound $\mathbf{L} 1$ to form an allenylidene intermediate (A). Subsequently, nucleophilic attack by the oxygen atom of methanol on the $\mathrm{C}_{\alpha}$ of the allenylidene followed by proton transfer at $\mathrm{C}_{\beta}$ gives the (methoxyalkenylcarbene)iridium intermediate 1a. Intramolecular $\mathrm{C}-\mathrm{H}$ activation then occurred after treatment with $\mathrm{AgPF}_{6}$ to remove another chloride and to generate the ultimate product complex 1. Fortunately, we successfully isolated the intermediate $\mathbf{1 a}$ and obtained its single crystal (Fig. S2 $\dagger$ ) to further verify the reaction mechanism we proposed above. In addition, it is well documented in the literature that carbene complexes like 1a could easily be formed from a reaction between allenylidene intermediates and alkynol pro-ligands. ${ }^{15}$ Additionally, the structure of the fluorenyl ligand of 1a was symmetric, so pure products could be obtained in the subsequent ring-closing reaction due to the equivalent $\mathrm{C}-\mathrm{H}$ activation sites $\left(\mathrm{H}_{\mathrm{a}}\right.$ and $\mathrm{H}_{\mathrm{b}}$ in Scheme $\left.\mathrm{S} 3 \dagger\right)$ in 1a. Interestingly, when asymmetric compounds (L7-L9) reacted with $\mathrm{Cp}^{*} \mathrm{IrCl}_{2}\left(\mathrm{PMe}_{3}\right)$, the corresponding pure complexes 79 were obtained in high yields above $90 \%$. In addition, we also successfully isolated carbene intermediates $7 \mathbf{a}$ and $\mathbf{8 a}$ and obtained their structures by single crystal X-ray crystallography (Fig. S3†). The complexes 7-9 were obtained by $\mathrm{CH}$ metalation of the benzene ring that is directly fused to the fivemembered ring and remote from the fused ring " $\mathrm{f}$ ". Metalation of this benzene ring results in the formation of a sixmembered metallacyclic ring. Presumably this is favoured over $\mathrm{CH}$ metalation of the fused benzene ring " $\mathrm{f}$ " because metalation of this ring would give a seven-membered metallacycle, the formation of which is expected to be less favourable. After treating $\mathbf{8 a}$ with $\mathrm{AgPF}_{6}$, ring-closed product $\mathbf{8}$ was successfully produced in a high yield of $93 \%$.

The structures of complexes 1-9 were verified by using nuclear magnetic resonance (NMR) spectroscopy and highresolution mass spectrometry (HRMS). Typically, for complex $\mathbf{1}$, the proton signals corresponding to the pentamethylcyclopentadienyl group can be observed at $\delta=1.84 \mathrm{ppm}$ and the ${ }^{13} \mathrm{C}\left(\mathrm{CH}_{3}\right)$ signals are located at $\delta=100.0$ and $9.7 \mathrm{ppm}$, respectively. The characteristic signals of group $\mathrm{P}\left(\mathrm{CH}_{3}\right)_{3}$ are located at $\delta=1.21 \mathrm{ppm}$ in the ${ }^{1} \mathrm{H}$ NMR spectrum and at $\delta=13.8$ $\operatorname{ppm}\left(\mathrm{d},{ }^{1} J_{\mathrm{C}-\mathrm{P}}=41.6 \mathrm{~Hz}\right)$ in the ${ }^{13} \mathrm{C}$ NMR spectrum, respectively. The ${ }^{31} \mathrm{P}$ NMR spectrum also shows two signals at $-35.3 \mathrm{ppm}(\mathrm{s}$, $\left.P\left(\mathrm{CH}_{3}\right)_{3}\right)$ and $-144.3 \mathrm{ppm}$ (hept, ${ }^{1} J_{\mathrm{P}-\mathrm{F}}=712.3 \mathrm{~Hz}, P \mathrm{~F}_{6}$ ), respectively. Additionally, the downfield signal observed at $\delta=$ $250.5 \mathrm{ppm}$ in the ${ }^{13} \mathrm{C}$ NMR spectrum corresponds to $\mathrm{C} 1$, which is a typical metal-bonded carbon atom. Similar spectra were obtained for complexes 2-9 and their NMR data were consistent with those reported in the literature. ${ }^{6 b, c, 8}$

We successfully obtained single crystals of 1-3, 5, 6, 8 and 9 to further confirm their structures. As shown in Fig. 1a and b, the tetracyclic skeleton of complex 1 exhibited good planarity. The sum of the angles in the iridium-containing six-membered ring was $720.0^{\circ}$, which is consistent with the ideal value of a planar six-membered ring. The bond lengths of Ir1-C1 and Ir1-C5 were 1.984 and $2.056 \AA$, respectively, while the corresponding bond lengths in complexes 2, 3, 5, 6, 8 and 9 were 1.954-1.992 $\AA$ and 2.034-2.071 $\AA$, respectively. These bond 
a

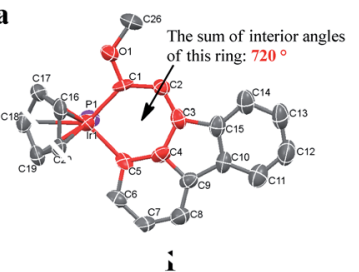

c

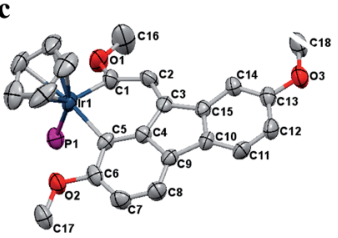

2
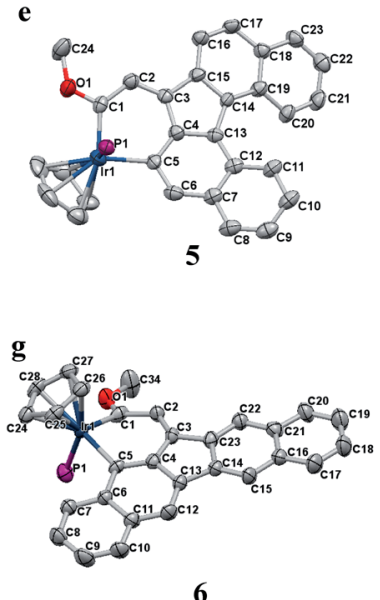

6

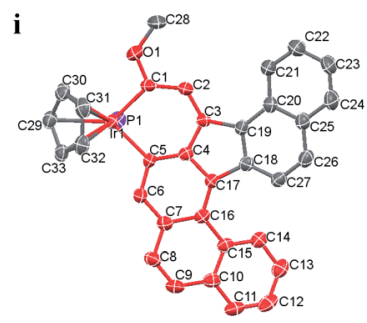

9 b

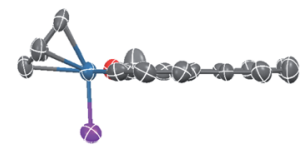

front view of 1

d

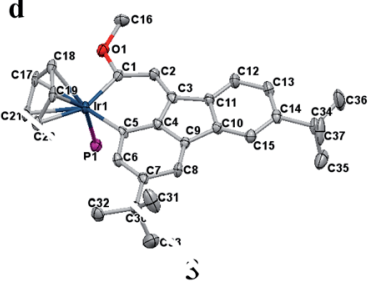

f

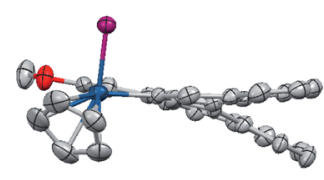

front view of 5

$\mathbf{h}$

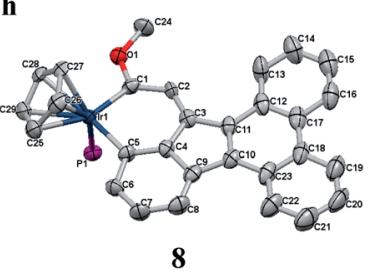

j

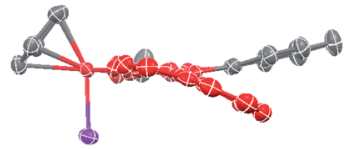

front view of 9

Fig. 1 Molecular structure of 1 (a and b), 2 (c), 3 (d), 5 (e and f), 6 (g), 8 (h) and 9 ( $i$ and j) (thermal ellipsoids set at $50 \%$ probability). Hydrogen atoms and the methyl group in $\mathrm{Cp}^{*}$ and $\mathrm{PMe}_{3}$ are omitted for clarity.

lengths are also comparable to the values of the previously reported systems including iridanaphthalene, ${ }^{6}$ iridaphenanthrene and iridaanthracene. ${ }^{7,8}$ In addition, as an iridafluoranthene derivative, complex 1 can be considered to be composed of an iridanaphthalene moiety and a benzene ring linked by a fused five-membered ring. In the crystal structure of 2 (Fig. 1c), the sum of the angles in the iridium-containing sixmembered ring was $711.4^{\circ}$, indicative of a slightly lower planarity compared with $\mathbf{1}$. This may be due to the steric hindrance between the methoxy group (bonded to C6 and C13) and the pentamethylcyclopentadienyl group, which makes the iridium atom stand slightly out of the plane formed by $\mathrm{C} 1-\mathrm{C} 2-$

C3-C4-C5. The iridium-containing polycyclic skeletons observed in the crystal structures of 3, 6 and 8 also show excellent planarity (Fig. 1d, $\mathrm{g}$ and $\mathrm{h}$ ), while the polycyclic frameworks of 5 and 9 exhibit some distortion (Fig. 1e, f, i and $\mathrm{j}$ ), which is presumably caused by the intramolecular repulsion between the hydrogen atoms connected with C12 and C20 in 5 and $\mathrm{C} 14$ and $\mathrm{C} 27$ in 9.

The UV-vis spectra of complexes 1-9 are illustrated in Fig. 2. Complexes 1-4 displayed similar absorption profiles with the maximum peak at around $400 \mathrm{~nm}$. Comparatively, the absorption bands of complexes 5-9 were located at 430-470 nm with an obvious red shift compared with complex 1 . These results clearly indicate that increasing the conjugation degree of metallaaromatic rings can effectively increase their corresponding absorption wavelength, while introducing different substituent groups has no significant influence on their absorption. In addition, tails were observed for complexes 1-9 similar to those observed for pure organic fluoranthene derivatives, ${ }^{\mathbf{1 6}}$ while these tails were broader and their positions were significantly red-shifted compared with those for pure fluoranthene derivatives due to the presence of iridium atoms. Therefore, TD-DFT calculations were performed to confirm the above observations and the pertinent data are collected in Table 1 and Table 2. The simulated absorption spectra of complexes 1-9 are well consistent with the experimental data. According to the TD-DFT results, the absorptions of all complexes are attributed to the transitions from HOMO-4 or HOMO-2 (8) to the LUMO, which were mainly involved in the intra-ligand and metal (Ir) to ligand transitions, further verifying the significant role of the metal atoms.
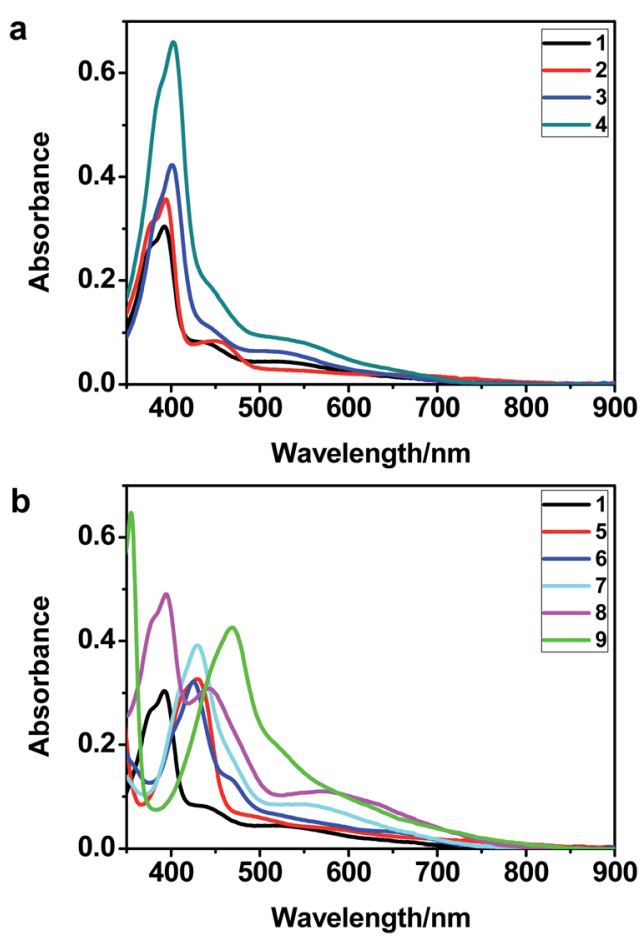

Fig. $2 \mathrm{UV} / \mathrm{vis}$ absorption spectra of complexes $1-9\left(2.0 \times 10^{-5} \mathrm{M}\right)$ measured in $\mathrm{CH}_{2} \mathrm{Cl}_{2}$ at room temperature. 
Table 1 Detailed photophysical data and calculation results

\begin{tabular}{|c|c|c|c|c|c|c|}
\hline Compound & $\lambda_{\text {abs }} / \mathrm{nm}$ calc. (exp.) & Excitation & $f$ & Percentage & $1^{\text {st }} E_{\text {red }} v s . \mathrm{Fc}^{+/ 0}(\mathrm{~V})$ & $1^{\text {st }} E_{\text {oxi }} v s . \mathrm{Fc}^{+/ 0}(\mathrm{~V})$ \\
\hline 1 & 379 (393) & HOMO-4 $\rightarrow$ LUMO & 0.4074 & $91 \%$ & -1.21 & 0.98 \\
\hline 2 & $378(394)$ & HOMO $-4 \rightarrow$ LUMO & 0.3799 & $94 \%$ & -1.24 & 0.72 \\
\hline 4 & $398(402)$ & HOMO- $4 \rightarrow$ LUMO & 0.4158 & $70 \%$ & -1.05 & 1.09 \\
\hline 5 & $420(429)$ & HOMO- $4 \rightarrow$ LUMO & 0.1776 & $65 \%$ & -0.99 & 0.83 \\
\hline 6 & $422(425)$ & HOMO-4 $\rightarrow$ LUMO & 0.3625 & $78 \%$ & -1.20 & 0.97 \\
\hline & $377(394)$ & HOMO $-5 \rightarrow$ LUMO & 0.3277 & $76 \%$ & & \\
\hline 9 & $482(468)$ & HOMO-4 $\rightarrow$ LUMO & 0.2385 & $64 \%$ & -0.97 & 0.94 \\
\hline
\end{tabular}

To gain insight into the electronic properties of these complexes, cyclic voltammetry (CV) was performed in dichloromethane using a platinum disk as the working electrode, a platinum wire as the counter electrode and an $\mathrm{Ag}$ wire as the reference electrode. All complexes showed multielectron redox processes (Fig. 3) and only their first reduction

Table 2 Selected molecular orbitals and energy levels of complexes 1-9

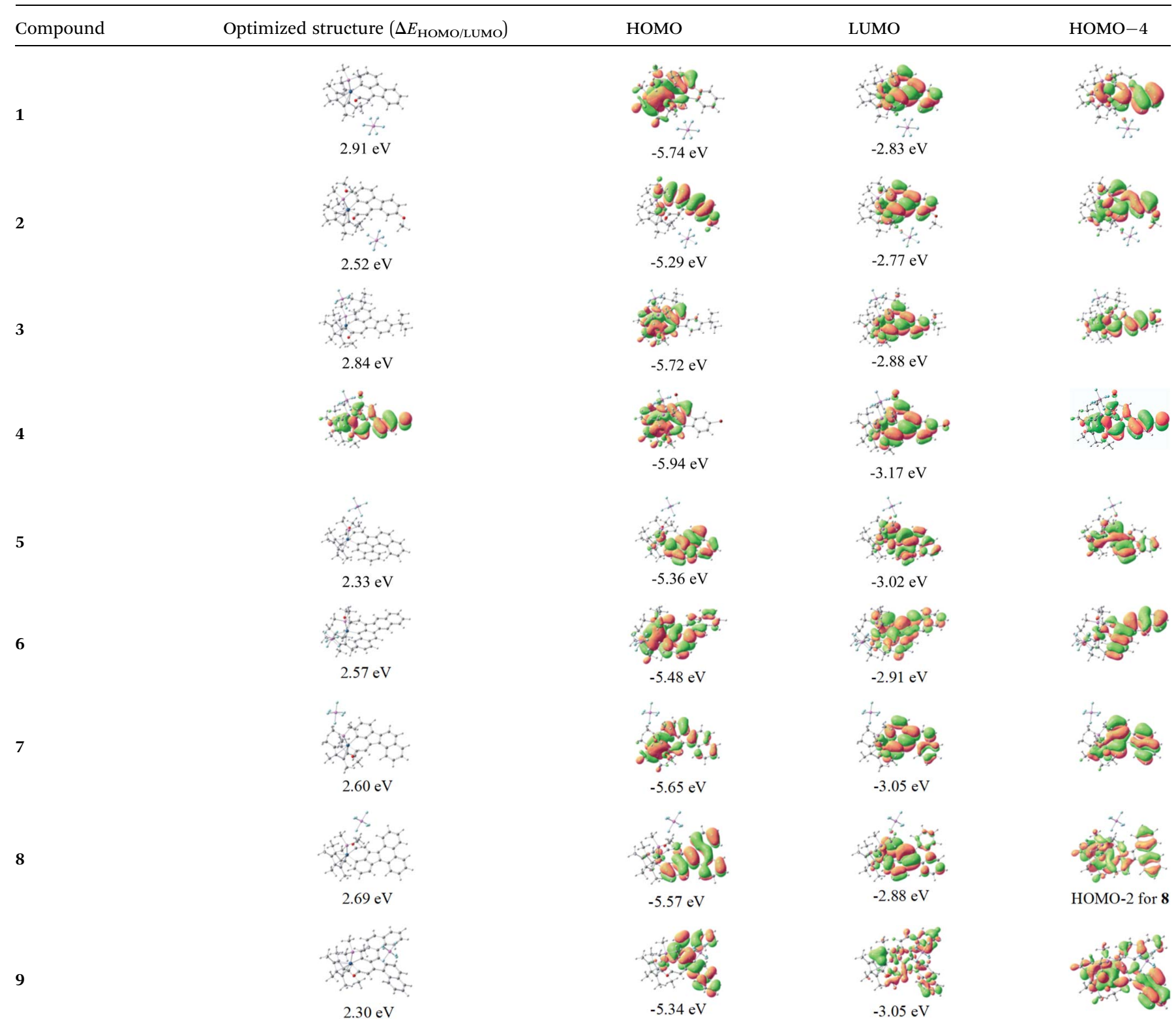


a
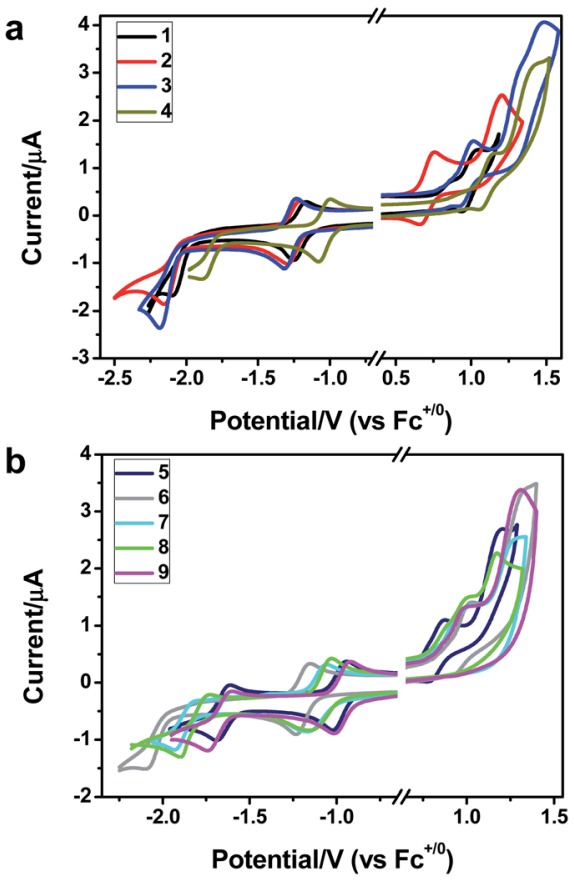

Fig. 3 Cyclic voltammograms of complexes $1-9\left(2.0 \times 10^{-3} \mathrm{M}\right)$ measured in $\mathrm{CH}_{2} \mathrm{Cl}_{2}$ at room temperature $\left(0.1 \mathrm{M}, n-\mathrm{Bu}_{4} \mathrm{NPF}_{6}\right)$.

processes were reversible (Fig. S1†). As presented in Table 1, the introduction of electron-donating $-\mathrm{OCH}_{3}$ and $t$-Bu groups in complexes 2 and 3, respectively, caused a cathodic shift in the reduction potential compared with that in $\mathbf{1}$, while the electronwithdrawing bromine atom in complex 4 led to an anodic shift. For complexes 5-9, the extension of conjugated fused rings resulted in anode-shifted reduction potentials and cathodeshifted oxidation potentials, and especially the first reversible reduction potentials of 5 and 9 reached $-0.99 \mathrm{~V}$ and $-0.97 \mathrm{~V}$, respectively. As presented in Table 2, the calculated HOMO and LUMO levels also matched well with the changing tendencies of the first oxidation and reduction potentials, respectively. Taken together, introducing electron-donating groups increased both the HOMO and LUMO levels, while electron-withdrawing units resulted in an opposite effect; enlarging the $\pi$-skeletons decreased the LUMO level and increased the HOMO level. ${ }^{17}$

\section{Conclusions}

In summary, a series of novel iridafluoranthene derivatives as metalla-analogues of PAHs were synthesized in high yields under mild conditions by a one-pot synthetic route. In addition, fused rings ranging from four to seven in number were successfully obtained for the first time. Among them, metallaPAHs containing seven fused rings is a new record. Meanwhile, a sterically-oriented synthetic strategy was revealed and this new method may provide a feasible approach to prepare larger conjugated polycyclic metallaaromatic hydrocarbons or even multinuclear metalla-analogues of PAHs in high yields. In addition, introducing different substituent groups and enlarging the conjugation of the $\pi$-skeletons can effectively tune the electronic properties of metallaaromatics. Electrondonating groups can elevate both the HOMO and LUMO levels, while electron-withdrawing units will lead to an opposite effect. Enlarging the $\pi$-skeletons will decrease the LUMO level and increase the HOMO level. Therefore, our present results open up a new avenue for the design and synthesis of new polycyclic metallaaromatic hydrocarbons and metallananographenes.

\section{Conflicts of interest}

The authors declare no conflict of interest.

\section{Acknowledgements}

The authors gratefully acknowledge the financial support from the National Natural Science Foundation of China (21772054 and 21676113) and the 111 Project (B17019).

\section{Notes and references}

1 Q. Yan, Y. Zhou, B.-B. Ni, Y. Ma, J. Wang, J. Pei and Y. Cao, J. Org. Chem., 2008, 73, 5328-5339; R. C. Chiechi, R. J. Tseng, F. Marchioni, Y. Yang and F. Wudl, Adv. Mater., 2006, 18, 325-328; J. Dong, X. Li, K. Zhang, Y. D. Yuan, J. Jiang and D. Zhao, J. Am. Chem. Soc., 2018, 140, 4035-4046; G. M. Paternò, Q. Chen, X.-Y. Wang, K. Müllen, A. Narrita and F. Scotognella, Angew. Chem., Int. Ed., 2017, 56, 67536757.

2 (a) S. Allard, M. Forster, B. Souharce, H. Thiem and U. Scherf, Angew. Chem., Int. Ed., 2008, 47, 4070-4098; (b) C. Wang, H. Dong, W. Hu, Y. Liu and D. Zhu, Chem. Rev., 2012, 112, 2208-2267; (c) M. D. Watson, A. Fechtenkötter and K. Müllen, Chem. Rev., 2001, 101, 1267-1300.

3 (a) J. Farinhas, D. Molina, A. Olcina, C. Costa, F. FernándezLázaro, Á. Sastre-Santos and A. Charas, Dyes Pigm., 2019, 161, 188-196; (b) H. Wu, L. Yang, Y. Li, M. Zhang, Y. Guo and P. Wang, J. Mater. Chem. A, 2016, 4, 519-528.

4 G. P. Elliott, W. R. Roper and J. M. Waters, J. Chem. Soc., Chem. Commun., 1982, 811-813.

5 (a) X.-Y. Cao, Q. Zhao, Z. Lin and H. Xia, Acc. Chem. Res., 2014, 47, 341-354; (b) A. F. Dalebrook and L. J. Wright, Adv. Organomet. Chem., 2012, 60, 93-177; (c) B. J. Frogly and L. J. Wright, Chem.-Eur. J., 2018, 24, 2025-2038.

6 (a) M. Paneque, C. M. Posadas, M. L. Poveda, N. Rendón, V. Salazar, E. Oñate and K. Mereiter, J. Am. Chem. Soc., 2003, 125, 9898-9899; (b) M. Talavera, S. Bolaño, J. Bravo, J. Castro, S. García-Fontán and J. M. Hermida-Ramón, Organometallics, 2013, 32, 4058-4060; (c) M. Talavera, J. Bravo, J. Castro, S. García-Fontán, J. M. Hermida-Ramón and S. Bolaño, Dalton Trans., 2014, 43, 17366-17374.

7 B. J. Frogly and L. J. Wright, Angew. Chem., Int. Ed., 2017, 56, 143-147.

8 M. Talavera, A. Peña-Gallego, J. L. Alonso-Gómez and S. Bolaño, Chem. Commun., 2018, 54, 10974-10976. 
9 (a) J. Chen, C. Shi, H. H. Y. Sung, I. D. Williams, Z. Lin and G. Jia, Angew. Chem., Int. Ed., 2011, 50, 7295-7299; (b) J. Chen and G. Jia, Coord. Chem. Rev., 2013, 257, 2491-2521. 10 (a) G. He, J. Zhu, T. B. Wen, I. D. Williams, Z. Lin and G. Jia, Angew. Chem., Int. Ed., 2007, 46, 9065-9068; (b) B. Liu, H. Xie, Q. Zhao, J. Chen, T. B. Wen, Z. Cao and H. Xia, Angew. Chem., Int. Ed., 2009, 48, 5461-5464; (c) M.-X. Zhang, J. Zhang, X. Jin, X. Sun, J. Yin, F. Hartl and S. H. Liu, Chem.-Eur. J., 2018, 24, 18998-19009.

11 (a) M.-X. Zhang, Z. Xu, T. Lu, J. Yin and S. H. Liu, Chem.-Eur. J., 2018, 24, 14891-14895; (b) W. Ruan, T.-F. Leung, C. Shi, I. D. Williams, Z. Lin and G. Jia, Chem. Sci., 2018, 9, 59945998.

12 (a) C. Zhu, M. Luo, Q. Zhu, J. Zhu, P. R. Schleyer, J. I.-C. Wu, X. Lu and H. Xia, Nat. Commun., 2014, 5, 3265-3271; (b) C. Zhu, X. Zhou, H. Xing, K. An, J. Zhu and H. Xia, Angew. Chem., Int. Ed., 2015, 54, 3102-3106; (c) C. Zhu, J. Zhu, X. Zhou, Q. Zhu, T. B. Wen and H. Xia, Angew. Chem., Int. Ed., 2018, 57, 3154-3157.

13 (a) R. Li, Z. Lu, Y. Cai, F. Jiang, W. Hong and H. Xia, J. Am. Chem. Soc., 2017, 139, 14344-14347; (b) C. Zhu, Q. Zhu,
J. Zhu, X. He, X.-Y. Cao and H. Xia, Angew. Chem., Int. Ed., 2014, 53, 6232-6236.

14 M. Talavera, S. Bolaño, J. Bravo, J. Castro, S. García-Fontán and J. M. Hermida-Ramón, Organometallics, 2013, 32, 4402-4408.

15 (a) M. A. Esteruelas, A. V. Gómez, A. M. López, E. Oñate and N. Ruiz, Organometallics, 1998, 17, 2297-2306; (b) M. A. Esteruelas, A. V. Gómez, A. M. López, M. Oliván, E. Oñate and N. Ruiz, Organometallics, 2000, 19, 4-14; (c) B. Weberndörfer and H. Werner, J. Chem. Soc., Dalton Trans., 2002, 1479-1486; (d) A. Asensio, M. L. Buil, M. A. Esteruelas and E. Oñate, Organometallics, 2004, 23, 5787-5798.

16 G. S. Mohammad-Pour, R. T. Ly, D. C. Fairchild, A. Burnstine-Townley, J. K. Harper and F. J. Uribe-Romo, J. Org. Chem., 2018, 83, 8036-8053.

17 (a) C. Yan, S. Barlow, Z. Wang, A. K. Y. Jen, S. R. Marder and X. Zhan, Nat. Rev. Mater., 2018, 3, 18003; (b) A. Nowak-Król, K. Shoyama, M. Stolte and F. Würthner, Chem. Commun., 2018, 54, 13763-13772; (c) J. M. Farrell, C. Mützel, D. Bialas, M. Rudolf, A.-M. Krause, M. Stolte and F. Würthner, J. Am. Chem. Soc., 2019, 141, 9096-9104. 